\title{
Transport of Malic Acid in the Yeast Schizosaccharomyces pombe: Evidence for a Proton-Dicarboxylate Symport
}

\author{
MARIA JOÃO SOUSA, MANUEL MOTA* AND CECÍLIA LEÃO† \\ Center of Chemical Engineering, University of Porto, 4099 Porto Codex, Portugal \\ * Department of Engineering Sciences-Biological Engineering, University of Minho, 4719 Braga Codex, Portugal \\ $\dagger$ Laboratory of Biology, University of Minho, 4719, Braga Codex, Portugal
}

Received 13 March 1992; accepted 9 May 1992

\begin{abstract}
The transport system for malic acid present in Schizosaccharomyces pombe cells, growing in batch culture on several carbon sources, has been studied. It was found that the dicarboxylic acid carrier of $S$. pombe is a proton-dicarboxylate symporter that allows uphill transport and accumulation as a function of $\Delta \mathrm{pH}$ with the following kinetic parameters at pH 5.0: $V_{\max }=0.1 \mathrm{nmol}$ of total malic acid s ${ }^{-1} \mathrm{mg}$ (dry weight) of cells ${ }^{-1}$ and $K_{\mathrm{m}}=1.0 \mathrm{~mm}$ total malic acid. Malic acid uptake ( $\mathrm{pH} 5.0$ ) was accompanied by disappearance of extracellular protons, the uptake rates of which followed Michaelis-Menten kinetics as a function of the acid concentration. The $K_{\mathrm{m}}$ values calculated as the concentrations either of anions or of undissociated acid, at various extracellular $\mathrm{pH}$ values, pointed to the monoanionic form as the transported species. Furthermore, accumulated free acid suffered rapid efflux after the addition of the protonophore carbonyl cyanid $m$-chlorophenyl hydrazone. These results suggested that the transport system was a dicarboxylateproton symporter. Growth of cells in a medium with glucose (up to $14 \%$, w/v) and malic acid ( $1 \cdot 5 \%$, w/v) also resulted in proton-dicarboxylate activity, suggesting that the system, besides being constitutive, was still active at high glucose concentrations. The following dicarboxylic acids acted as competitive inhibitors of malic acid transport at $\mathrm{pH} 5 \cdot 0: \mathrm{D}-$ malic acid, succinic acid, fumaric acid, oxaloacetic acid, $\alpha$-ketoglutaric acid, maleic acid and malonic acid. In addition, all of these dicarboxylic acids induced proton movements that followed Michaelis-Menten kinetics. It was concluded that the malic negatively charged form (probably the monoanionic form) was transported by a proton-symport mechanism and that the carrier appeared to be a common 'dicarboxylate transport system'. The undissociated acid entered the cells slowly by simple diffusion.
\end{abstract}

KEY WORDS - Schizosaccharomyces; malic acid; transport.

\section{INTRODUCTION}

L-Malic acid and other dicarboxylic acids are transported across the plasma membrane by proton symports which are inducible and subject to glucose repression, in Candida sphaerica (Côrte-Real et al., 1989), and Hansenula anomala (Côrte-Real and Leão, 1990). These yeast species are able to use L-malic acid as sole carbon and energy sources. However, a similar pattern for dicarboxylic acids transport has not been found in Saccharomyces cerevisiae, Zygosaccharomyces bailii and Schizosaccharomyces pombe, yeast species which can only metabolize L-malic acid if glucose is present (Rodriguez and Thornton, 1990). Earlier studies have provided evidence that transport of malic acid

†Addressee for correspondence.

0749-503X/92/121025-07\$08.50

() 1992 by John Wiley \& Sons Ltd is not carrier-mediated in $S$. cerevisiae (Salmon, $1987)$ and is carrier-mediated in $Z$. bailii (Baranowski and Radler, 1984). In S. pombe, evidence for a mediated transport for malic acid has been reported (Osothsilp and Subden, 1986). However, malic acid transport in this yeast has not been studied in detail, particularly regarding the acid (anions/undissociated acid) transport mechanism and the substrate specificity of the carrier. Furthermore, no attempt has been made to elucidate the malic acid transport when the yeast is growing in the presence of high glucose concentration. Besides its academic interest, the subject may have a practical dimension since the yeast $S$. pombe, which is able to convert malic acid to ethanol (the so-called maloalcoholic fermentation), has been proposed for grape must deacidification. 
In the present work we report on the transport of L-malic acid and other dicarboxylic acids across the plasma membrane in a strain of the yeast $S$. pombe and provide experimental evidence indicating that the malic acid carrier of the yeast constitutes a proton-dicarboxylate symport mechanism, the carrier remaining operational when the yeast is growing under conditions similar to those employed in wine-making.

\section{MATERIALS AND METHODS}

\section{Microorganism and growth conditions}

The $S$. pombe ICV'M strain used was isolated from wine in ICV of Montpelier (Auriol et al., 1987). It was maintained in a medium containing glucose $(2 \%, w / v)$, peptone $(1 \%, w / v)$, yeast extract $(0.5 \%, w / v)$ and agar $(2 \%, w / v)$. For growth, a mineral medium with vitamins (van Uden, 1967), supplemented with the carbon sources, was used as described in Results.

\section{Measurement of initial uptake rates}

Cells were harvested in mid-exponential phase, centrifuged, washed twice with ice-cold distilled water and suspended in distilled water to a final concentration of about $80 \mathrm{mg}$ dry weight $/ \mathrm{ml}$.

Preliminary results showed that malic acid and succinic acid were accepted by the same carrier in glucose-grown cells. The uptake rates of dicarboxylic acid were measured using $\mathrm{L}-\left[\mathrm{U}-{ }^{14} \mathrm{C}\right] \mathrm{malic}$ acid or $\left[2,3-{ }^{14} \mathrm{C}\right]$ succinic acid. To estimate the uptake rates, $10 \mu \mathrm{l}$ amounts of the yeast suspension were mixed in $10 \mathrm{ml}$ conical tubes with $30 \mu \mathrm{l}$ of $0.1 \mathrm{M}$-phosphate buffer at the desired $\mathrm{pH}$ value. After 2 min of incubation in a water bath, at $25^{\circ} \mathrm{C}$, the reaction was started by the addition of $10 \mu \mathrm{l}$ of an aqueous solution of $\mathrm{L}-\left[\mathrm{U}-{ }^{14} \mathrm{C}\right] \mathrm{malic}$ acid or $\left[2,3-{ }^{14} \mathrm{C}\right]$ succinic acid at the desired concentration and stopped by dilution with $5 \mathrm{ml}$ of ice-cold water. Sampling times were 0,5 and $10 \mathrm{~s}$. Sampling times for simple diffusion studied at $\mathrm{pH} 2.0$ were 0,30 and $60 \mathrm{~s}$. The reaction mixtures were immediately filtered through GF/C filters (Whatman, Inc., Clifton, NJ), washed on the filters with $10 \mathrm{ml}$ of ice-cold water, and counted in scintillation fluid (OptiPhase HiSafe II; LKB Scintillation Products). Radioactivity was measured with a liquid scintillation counter $(2200$ CA; Packard Instrument Co., Inc., Rockville, MD).

Uptake rates were also calculated from measurements of the proton uptake with a standard $\mathrm{pH}$ meter (PHM 82; Radiometer A/S, Copenhagen,
Denmark) connected to a Perkin-Elmer R $100 \mathrm{~A}$ recorder (Perkin-Elmer Corp., Norwalk, Conn.). The $\mathrm{pH}$ electrode was immersed in a water-jacketed chamber provided with magnetic stirring. To the chamber were added $4.5 \mathrm{ml}$ of $10 \mathrm{~mm}$-phosphate buffer and $0.5 \mathrm{ml}$ of yeast suspension. The $\mathrm{pH}$ was ajusted to the desired value, and a baseline was obtained. The desired amount of dicarboxylic acid (adjusted to the experimental $\mathrm{pH}$ value) was added, and the subsequent alkalinization was monitored with the recorder. The initial uptake rate was calculated from the slope of the initial part of the $\mathrm{pH}$ trace. Calibration was performed with $\mathrm{HCl}$.

\section{Measurement of the intracellular volume}

The intracellular volume was measured as previously described (De La Peña et al., 1981; Rottenberg, 1979). Using glucose-grown cells, a value of $1.7 \mu \mathrm{l}$ of intracellular water per milligram dry weight of the yeast was estimated.

\section{Measurement of dicarboxylic acid accumulation}

Glucose-grown cells $(20 \mu \mathrm{l} ; 80 \mathrm{mg}$ dry weight $\mathrm{ml}^{-1}$ ) were added to $60 \mu \mathrm{l}$ of $0 \cdot 1 \mathrm{M}$-phosphate buffer (pH 3.0 or 5.0 ) and also to $60 \mu \mathrm{l}$ of buffer containing carbonyl cyanid $m$-chlorophenyl hydrazone (CCCP) and were incubated at $25^{\circ} \mathrm{C}$ with magnetic stirring. The reaction was started by the addition of $20 \mu \mathrm{l}$ of $6.5 \mathrm{mM}-\mathrm{L}-\left[\mathrm{U}-{ }^{14} \mathrm{C}\right] \mathrm{malic}$ acid (about $5000 \mathrm{dpm} / \mathrm{nmol}$ ). At appropriate times, $5 \mu \mathrm{l}$ was taken from the reaction mixture, diluted with $5 \mathrm{ml}$ of ice-cold water and filtered immediately through Whatman GF/C filters. The filters were washed twice with $5 \mathrm{ml}$ of ice-cold water and radioactivity was counted as indicated above.

The intracellular concentration of L-malic acid was calculated using the value of intracellular volume estimated as described above.

\section{Calculation of concentrations}

Concentrations of the several ionization forms of the carboxylic acids were calculated by the Henderson-Hasselbach equation with the following $p K$ values: malic acid $p K_{1}=3.40$ and $p K_{2}=5.05$; succinic acid $p K_{1}=4 \cdot 18$ and $p K_{2}=5.56$.

Calculation of the kinetic parameters for the mediated transport system

Estimates of kinetic parameters were obtained from the Lineweaver-Burk plots of the initial uptake 
rates of radiolabelled malic or succinic acids, as well as of the initial rates of proton disappearance in the external buffer. The $K_{\mathrm{m}}$ for total dicarboxylic acids was based on the concentrations of both anionic and undissociated dicarboxylic acid. The $K_{\mathrm{m}}$ values for facilitated diffusion of the undissociated acid or for the proton-dicarboxylate symport were based on the concentration of undissociated dicarboxylic acid or anionic forms, respectively, that would be present at the experimental $\mathrm{pH}$ value. The contribution of the simple diffusion of the undissociated acid at low $\mathrm{pH}$ values was estimated as described in Results.

\section{Reproducibility of the results}

All the experiments were repeated at least three times, and the data reported here are the average values.

\section{Chemicals}

Radioactively labelled malic acid and succinic acid were obtained from the Radiochemical Centre (Amersham, Buckinghamshire, UK) and had the following specific activities: L-[U- $\left.{ }^{14} \mathrm{C}\right]$ malic acid, $51.4 \mathrm{mCi} / \mathrm{mmol} ;\left[2,3-{ }^{14} \mathrm{C}\right]$ succinic acid, $116 \mathrm{mCi} /$ $\mathrm{mmol}$. All other chemicals were reagent grade and were obtained from commercial sources.

\section{RESULTS}

Transient external alkalinization indicative of proton uptake was observed when malic acid or succinic acid were added to suspensions of cells in weak buffer ( $\mathrm{pH} 5.0$ ) that had been grown on glucose medium $(2 \%, w / v)$. Lineweaver-Burk plots of the initial rates of proton disappearance in the external buffer, calculated from the initial slopes of the $\mathrm{pH}$ curves, as well as Lineweaver-Burk plots of the initial rates of uptake of radiolabelled L-malic or succinic acid ( $\mathrm{pH} 5 \cdot 0$ ), were linear over the concentration range 0.1 to $6.5 \mathrm{~mm}$. From the plots for uptake of labelled substrates, the following kinetic parameters were calculated, as described in Materials and Methods: for total malic acid, $V_{\max }$ (pH 5.0) $=0.1 \pm 0.03 \mathrm{nmol} \mathrm{s}^{-1} \mathrm{mg}$ (dry weight) cells $^{-1} ; K_{\mathrm{m}}(\mathrm{pH} 5 \cdot 0)=1 \cdot 0 \pm 0 \cdot 1 \mathrm{mM}$; for total succinic acid, $V_{\max }(\mathrm{pH} 5.0)=0.20 \pm 0.05 \mathrm{nmol} \mathrm{s}^{-1} \mathrm{mg}$ (dry weight) cells ${ }^{-1} ; K_{\mathrm{m}}$ (pH 5.0) $=4.5 \pm 0.5 \mathrm{~mm}$. Figure 1 shows the results obtained for L-malic acid uptake. Identical results were obtained for succinic acid uptake, suggesting that the transport of either L- malic or succinic acid was mediated by a saturable carrier, possibly a proton symport. Both dicarboxylates were mutual competitive inhibitors, indicating that they shared the same carrier (Figure 2). D-malic acid, fumaric acid, oxaloacetic acid, $\alpha$-ketoglutaric acid, maleic acid and malonic acid were competitive inhibitors of succinic acid transport at $\mathrm{pH} 5.0$ (Figure 3). These results suggested that these acids were transported by the same carrier as L-malic acid. Indeed, those dicarboxylates induced proton uptake that followed Michaelis-Menten kinetics as a function of the concentration of the acids (results not shown). Lactic acid, pyruvic acid and citric acid did not act as competitive inhibitors of Lmalic acid transport, nor did they induce proton uptake, suggesting that these carboxylic acids were not transported by the dicarboxylate carrier of glucose-grown cells.

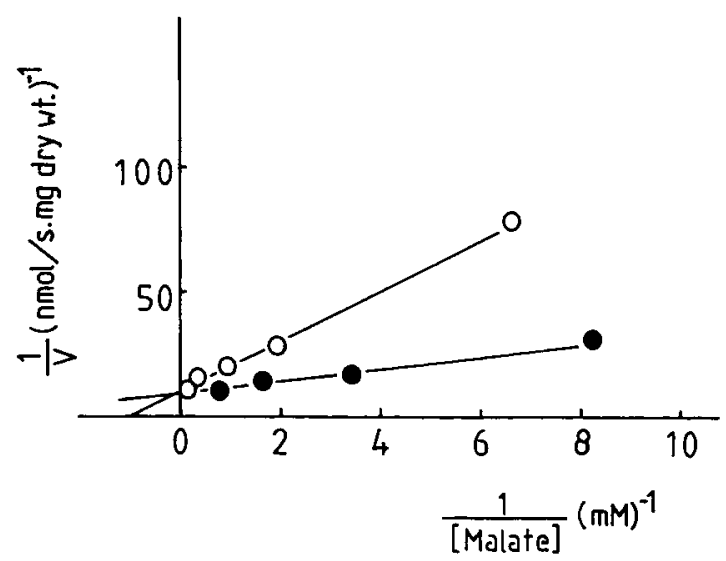

Figure 1. Lineweaver-Burk plots of initial uptake rates of labelled malic acid and protons by glucose-grown cells of $S$. pombe ICV'M at $\mathrm{pH} 5.0$ as a function of malate concentration. Symbols: $\bigcirc$, labelled malic acid acid; $\bullet$, protons.

Using glucose-grown cells, the initial transport rates of dicarboxylic acid were measured at extracelIular $\mathrm{pH}$ values lower than $5.0(\mathrm{pH} 4.0$ and 3.0$)$ with radioactive malic or succinic acids at concentrations up to $6.5 \mathrm{~mm}$. While at pH 5.0 , as described above, the transport of labelled dicarboxylic acid obeyed Michaelis-Menten kinetics, the experimental plot of the initial velocities against the concentration of the total malic acid, at lower $\mathrm{pH}$ range, indicated the presence of a mediated transport system but contaminated with a simple diffusion component, which could be vizualized by a shift from saturation at higher dicarboxylic acid concentrations (not shown). Since the relative concentration of undis- 


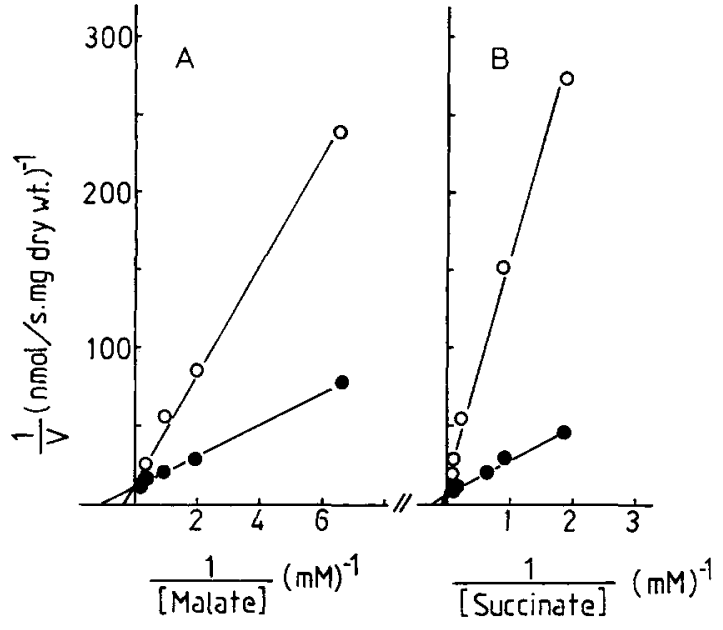

Figure 2. Lineweaver-Burk plots of initial uptake rates of (A) labelled malic acid as a function of malate concentration and (B) labelled succinic acid as a function of succinate concentration by glucose-grown cells of $S$. pombe ICV'M at pH 5.0. Symbols: the absence of other dicarboxylic acid; $O$, in the presence of $(A)$ $30 \mathrm{~mm}$-succinic acid and (B) $30 \mathrm{~mm}$-malic acid.

sociated acid increases with decreasing extracellular $\mathrm{pH}$, the mediated dicarboxylate transport probably coexisted in the lower $\mathrm{pH}$ range with a simple diffusion mechanism for the undissociated acid. In this case, the global kinetics would be expressed by the following equation:

$$
V=V_{\max } \frac{S}{K_{\mathrm{m}}+S}+k_{\mathrm{d}} S^{\prime}
$$

where $V_{\max }$ is the maximum transport capacity of the mediated transport system, $S$ is the concentration of dissociated dicarboxylic acid that would be present at the experimental $\mathrm{pH}$ value, $K_{\mathrm{m}}$ is the respective Michaelis constant, $S^{\prime}$ is the concentration of undissociated acid present at the same experimental $\mathrm{pH}$ value, and $k_{\mathrm{d}}$ is the rate constant of simple diffusion of undissociated acid. Using equation (1) and by iterative procedures, estimates of the Michaelis constants for the mediated dicarboxylate carrier without the contamination of the simple diffusion, at several $\mathrm{pH}$ values, were calculated (Table 1). As shown in this table, the variation of the $K_{\mathrm{m}}$ values between $\mathrm{pH} 3.0$ and 6.0 was over 248 -fold when calculated as the concentration of undissociated acid or dianionic form and less than four-fold when expressed as the concentration of monoanionic form, suggesting that the latter form of the acid was transported and that therefore the observed proton movements represented protonsymport activity.

The initial transport rates were also measured following $\mathrm{H}^{+}$uptake by a cell suspension after addition of malic or succinic acid at $\mathrm{pH}$ lower than 5.0 , as described in Materials and Methods. The Lineweaver-Burk plots of initial proton uptake rates at $\mathrm{pH} 4.5$ and 3.8 were linear in the experimental range from 0.03 to $0.3 \mathrm{~mm}$ (not shown). At $\mathrm{pH}$ lower than $3 \cdot 5$, given the high extracellular proton concentration, it was not possible to test the presence of $\mathrm{H}^{+}$uptake associated with the carboxylic acid uptake.

Transport of labelled malic acid at pH 5.0 was accumulative (Figure 4). After about $8 \mathrm{~min}, 80 \%$ of the accumulated radioactive substrate had not been metabolized, since the addition of cold malic acid induced counterflow to this extent (Figure 4). The accumulation ratio in terms of non-metabolized malic acid was about 11-fold. The protonophore CCCP prevented accumulation when added before the substrate and induced rapid efflux of accumulated non-metabolized malic acid (Figure 4). Similar results were obtained for the transport of labelled malic acid at $\mathrm{pH} 3 \cdot 5$. Furthermore, the inhibition of initial uptake rate of $0.1 \mathrm{~mm}$-labelled malic acid after an incubation of $30 \mathrm{~s}$ with $100 \mu \mathrm{M}-\mathrm{CCCP}$ at $\mathrm{pH}$ 3.0 was about $80 \%$, suggesting that the transport was dependent on the transmembrane proton-motive force. With respect to the specificity of the system, transport of labelled malic acid at $\mathrm{pH} 3.0$ displayed a similar behaviour to that observed at $\mathbf{p H} 5 \cdot \mathbf{0}$.

When the uptake of labelled succinic acid was measured at $\mathrm{pH} 2.0$ (relative concentration of the undissociated acid is near 100\%), the Eadie-Hofstee plot of the initial uptake rates of the undissociated acid transport was a vertical line (Figure 5). These observations were consistent with unidirectional diffusion kinetics of succinic acid across the plasma membrane. From this plot an estimate for the diffusion constant of $0.007 \mu \mathrm{s} \mathrm{s}^{-1}$ per mg (dry weight) cells was obtained. L-Malic acid did not act as a competitive inhibitor of succinic acid at $\mathrm{pH} 2 \cdot 0$, suggesting that the mediated malic acid transport described above was not measurable and that the form that probably entered the cells at this low $\mathrm{pH}$ was only the undissociated form.

Cells grown either in a medium with fructose $(2 \%, w / v)$ at $\mathrm{pH} 4.8$ or in a medium containing a mixture of glucose (up to $14 \%, \mathrm{w} / \mathrm{v}$ ) and malic acid $(1.5 \%, \mathrm{w} / \mathrm{v})$ at $\mathrm{pH} 4.8$ or $\mathrm{pH} 3.0$, formed a saturable transport system that mediated accumulative transport of L-malic acid, which appeared to be the 


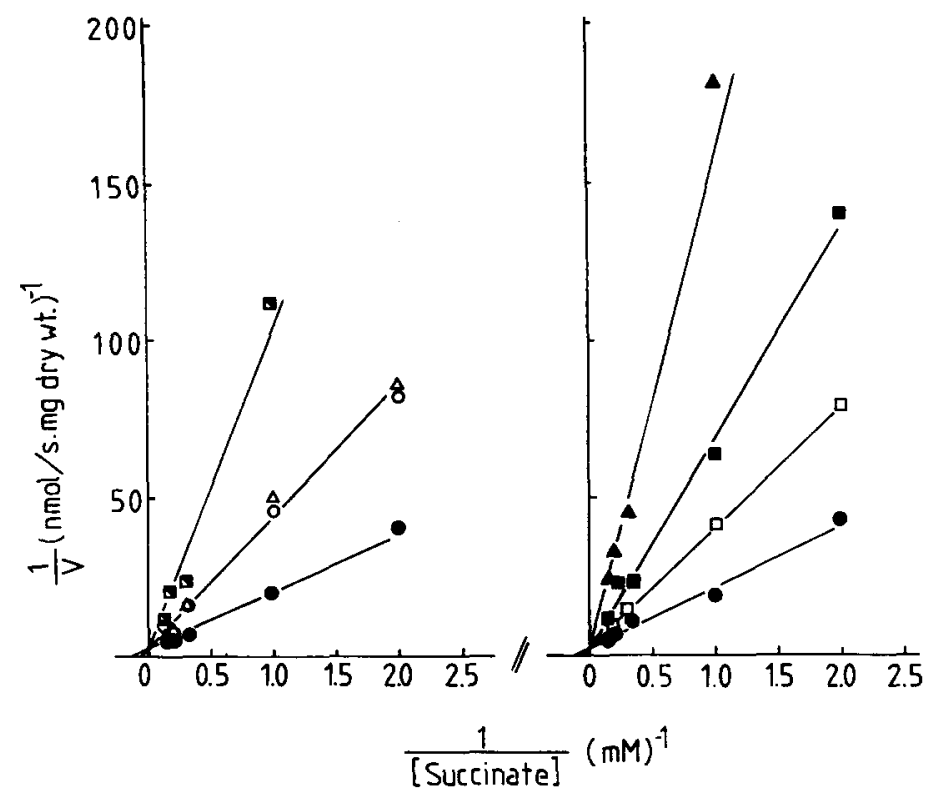

Figure 3. Lineweaver-Burk plots of initial uptake rates of labelled succinic acid at $\mathrm{pH} 5.0$ as a function of succinate concentration. Symbols: $\bullet$, in the absence of other dicarboxylic acid; $\nabla$ in the presence of $30 \mathrm{~mm}$-D-malic acid; $\Delta$, in the presence of $30 \mathrm{~mm}$-fumaric acid; $\Delta$, in the presence of $30 \mathrm{~mm}$-oxaloacetic acid; $O$, in the presence of $30 \mathrm{~mm}$ - $\alpha$-ketoglutaric acid; $\square$, in the presence of $30 \mathrm{~mm}$-maleic acid; $\boldsymbol{\square}$, in the presence of $30 \mathrm{~mm}$-malonic acid.

Table 1. Michaelis constants of labelled malic acid transport, in glucose-grown cells, as a function of extracellular $\mathrm{pH}^{*}$

\begin{tabular}{llll}
\hline $\begin{array}{l}\text { ph } \\
\text { out }\end{array}$ & $\begin{array}{c}\mathrm{A}^{2-} \\
K_{\mathrm{m}} \\
(\mathrm{mM})\end{array}$ & $\begin{array}{c}\mathrm{HA}^{-} \\
K_{\mathrm{m}} \\
(\mathrm{mM})\end{array}$ & $\begin{array}{c}\mathrm{H}_{2} \mathrm{~A} \\
K_{\mathrm{m}} \\
(\mathrm{mM})\end{array}$ \\
\hline 3.0 & 0.00041 & 0.052 & 0.124 \\
4.0 & 0.0235 & 0.263 & 0.050 \\
5.0 & 0.478 & 0.532 & 0.013 \\
6.0 & 1.78 & 0.190 & 0.0005 \\
\hline
\end{tabular}

*From Lineweaver-Burk plots of labelled malic acid, at each $\mathrm{pH}$, the $K_{\mathrm{m}}$ values, expressed as the different malic acid species concentrations, were calculated as described in Materials and Methods.

proton-malate symport described for glucose $(2 \%$, $\mathrm{w} / \mathrm{v})$-grown cells. According to the results obtained for all growth conditions described, the $\mathrm{H}^{+} /$ dicarboxylate transport system, besides being constitutive, remained operational, with the same activity, even in the presence of high glucose concentrations.

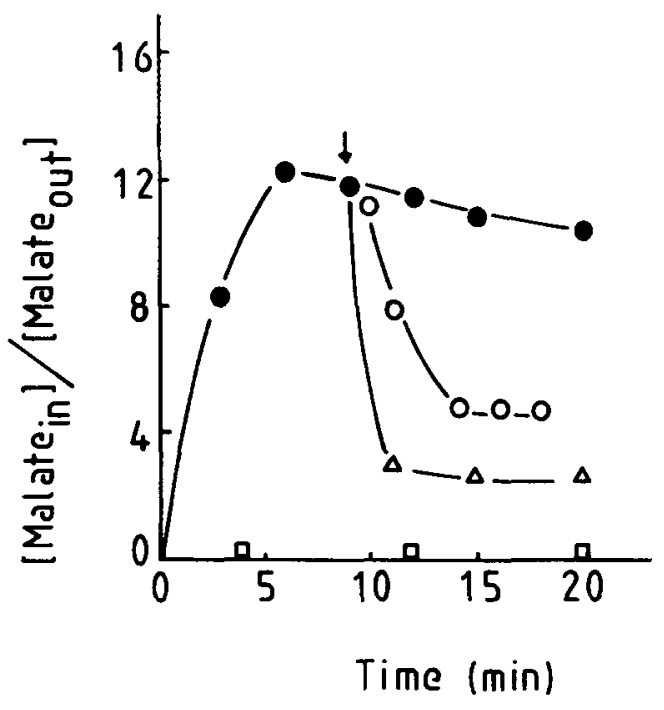

Figure 4. Accumulation of labelled malic acid $(\bullet)$ by glucosegrown cells of $S$. pombe ICV'M at pH 5.0. The initial extracellular concentration of total malic acid was $1.3 \mathrm{~mm}$. At the time indicated by the arrow, samples of the suspension received the following: $(\triangle)$, cold malic acid to a final concentration of $70 \mathrm{~mm}$; (O), CCCP to a final concentration of $0.1 \mathrm{~mm}$; and $(\square), \mathrm{CCCP}$ was added to the reaction mixture before the addition of labelled malic acid. 


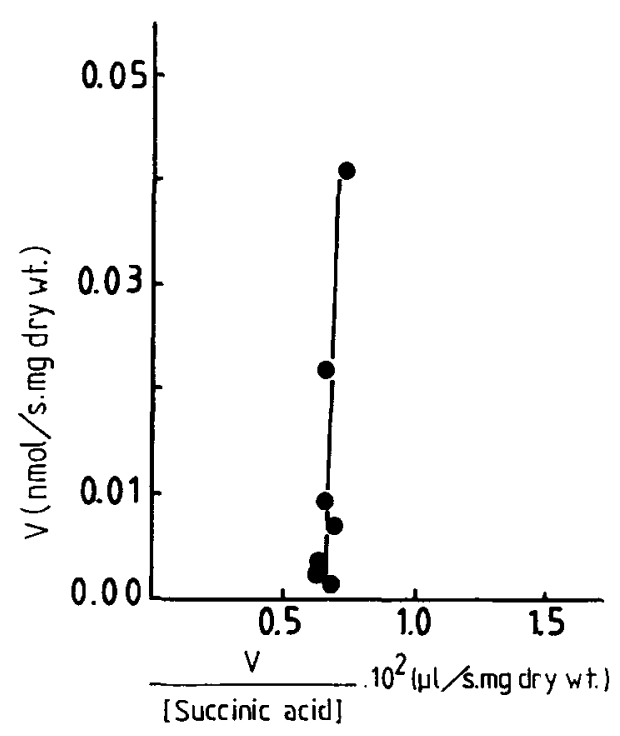

Figure 5. Eadie-Hofstee plot of initial uptake rates at $\mathrm{pH} 2.0$ of labelled succinic acid by glucose-grown cells of $S$. pombe ICV'M.

\section{DISCUSSION}

Evidence for a mediated transport for malic acid has been reported in $S$. pombe (Osothsilp and Subden, 1986). However, the malic acid transport mechanism was not completely elucidated and, as pointed out by the authors, further studies would be required to prove the possibility that a common dicarboxylic acid transport does exist in $S$. pombe as well as to elucidate the question of whether the monoanionic form of malate is the preferential substrate for transport. Furthermore, studies concerning the malic acid transport in cells grown under conditions similar to those used in wine-making have not been developed.

As for the mechanism involved, our results suggest that the dicarboxylic acid carrier of $S$. pombe is a proton-dicarboxylate symport that allows uphill transport and accumulation as a function of $\Delta \mathrm{pH}$. The common procedures to determine whether a substrate enters the cell by a protonsymport mechanism, are the evaluation of external transient alkalinization associated with the initial uptake of the substrate following Michaelis-Menten kinetics, as well as the measurement of the accumulation ratio of the non-metabolized substrate. In $S$. pombe, we found that the initial uptake of L-malic acid was accompanied by disappearance of extracellular protons, the rates of which followed MichaelisMenten kinetics as a function of the concentration of the acid. However, as previously discussed (Côrte-
Real et al., 1989), when the substrate is a weak carboxylic acid, the observation of proton uptake after addition of the acid, while consistent with the hypothesis of a proton-carboxylate symport, does not constitute final proof, since the facilitated diffusion of undissociated acid would lead to a similar observation. To distinguish between the two transport modes, the methodology previously described (Côrte-Real et al., 1989; Van Der Rest et al., 1991), based on the variation of $K_{\mathrm{m}}$ values with extracellular $\mathrm{pH}$, was used. The variation of the $K_{\mathrm{m}}$ values with extracellular $\mathrm{pH}$ (Table 1) was much less pronounced when expressed as the concentration of monoanionic form rather than undissociated acid or dianionic form, suggesting that the monoanionic form of the acid was transported. Transport of anions across the plasma membrane may be performed either by cotransport with cations or protons or by anion exchange (for a review see Stein, 1986). Our results suggest that the observed proton movements represent proton-symport activity.

Similarly, the observed accumulation of the dicarboxylic acid would also occur at external $\mathrm{pH}$ values lower than the intracellular $\mathrm{pH}$ if the undissociated acid was the transported form. However, the rapid efflux of accumulated radioactive dicarboxylic acid observed after the addition of the protonophore CCCP, which short-circuits the transmembrane proton-motive force, indicated that the transport and accumulation of labelled dicarboxylic acid were dependent on the transmembrane protonmotive force and that the dicarboxylic carrier is a proton-dicarboxylate symport, which allows uphill transport and accumulation as a function of $\mathrm{pH}$. With respect to the specificity of the proton-malate symport, the exhibited competitive inhibition of initial uptake rates of either labelled L-malic acid or labelled succinic acid by D-malic acid, fumaric acid, oxaloacetic acid, $\alpha$-ketoglutaric acid, maleic acid and malonic acid strongly suggest that these acids share the same carrier. Indeed, they all induced proton uptakes that followed Michaelis-Menten kinetics as a function of the concentration of the acids. Thus, we conclude that the malic negatively charged form (probably the monoanionic form) is transported by a proton-symport mechanism and that the carrier is a common "dicarboxylate transport system'. A linear component was detected at higher dicarboxylic acid concentrations and low $\mathrm{pH}$ values, which was interpreted as a simple diffusion of the undissociated acid through the lipid bilayer. It is interesting to note that while in yeasts that can use malic acid as a sole carbon and energy source, the 
acid enters the cells by proton-malate symports, which are subjected to induction and catabolic repression (Côrte-Real et al., 1989; Côrte-Real and Leão, 1990), in S. pombe, which can only metabolize L-malic acid if glucose is present, the proton-malate symport is constitutive. Furthermore, according to our results, the constitutive proton-malate symport of $S$. pombe remains active in the presence of high glucose concentrations. From the practical point of view, this ability is probably related to the great enological interest of $S$. pombe which has been often proposed for grape must deacidification processes.

\section{ACKNOWLEDGEMENTS}

This work was supported by a research grant from INIC (C.L.) and by research grants from FSE/JNICT and from NATO Science For Stability PO-PORTOFOOD (M.J.S. and M.M.).

\section{REFERENCES}

Auriol, P., Tulasi, S., Goma, G. and Strehaiano, P. (1987). Desacidification par Schizosaccharomyces pombe. Étude sur les aptitudes de differentes souches. Approche cinétique sur la degradation de l'acide málique. Revue Française de Oenologie 108, 37-42.

Baranowski, K. and Radler, F. (1984). The glucosedependent transport of L-malate in Zygosaccharomyces bailii. Antonie v. Leeuwenhoek 50, 329-340.
Côrte-Real, M., Leão, C. and van Uden, N. (1989). Transport of malic acid and other dicarboxylic acids in the yeast Candida sphaerica. Appl. Microbiol. Biotechnol. 31, 551-555.

Côrte-Real, M. and Leão, C. (1990). Transport of malic acid and other dicarboxylic acids in the yeast Hansenula anomala. Appl. Environ. Microbiol. 56, 1109-1113.

De La Pẽna, P., Barros, F., Gascon, S., Lazo, P. S. and Ramos, S. (1981). Effect of yeast killer toxin on sensitive cells of S. cerevisiae. J. Biol. Chem. 256, 10420-10425.

Osothsilp, C. and Subden, R. E. (1986). Malate transport in Schizosaccharomyces pombe. J. Bacteriol. 168, 1439-1443.

Rodriguez, S. B. and Thornton, R. J. (1990). Factors influencing the utilisation of $\mathrm{L}$-malate by yeasts. FEMS Microbiology Letters 72, 17-22.

Rottenberg, H. (1979). The measurement of membrane potential and $\mathrm{pH}$ in cells, organelles and vesicles. Meth. Enzymol. 55, 547-569.

Salmon, J. M. (1987). L-malic acid permeation in resting cells of anaerobically grown Saccharomyces cerevisiae. Biochim. Biophys. Acta 901, 30-34.

Stein, W. D. (1986). Transport and Diffusion Across Cell Membranes. Academic Press, Inc., London and San Diego.

Van Der Rest, M. E., Abee, T., Molenaar, D. and Konings, W. N. (1991). Mechanism and energetics of a citratetransport system of Klebsiella pneumonia. Eur. J. Biochem. 195, 71-77.

Van Uden, N. (1967). Transport limited fermentation and growth of Saccharomyces cerevisiae and its competitive inhibition. Arch. Microbiol. 58, 155-168. 